\title{
PENGARUH LATIHAN VARIASI SHOOTING KE ARAH GAWANG TERHADAP AKURASI SHOOTING DALAM PERMAINAN SEPAK BOLA PADA PEMAIN U-14 SSB TUNAS MUDA BENGKULU.
}

\author{
Ade Junaidi \\ Universitas Bengkulu \\ Adeneng2@gmail.com \\ Tono Sugihartono \\ Universitas Bengkulu \\ Ari Sutisyana \\ Universitas Bengkulu
}

\begin{abstract}
Abstrak
Penelitian ini bertujuan untuk mengetahui pengaruh latihan variasi shooting ke arah gawang terhadap akurasi shooting dalam permainan sepak bola. Populasi dalam penelitian ini adalah 30 pemain U-14 SSB Tunas Muda Bengkulu. Studi eksperimental menggunakan desain penelitian one group pretest-posttest design dengan teknik pengambilan sampel adalah total sampling, dimana seluruh populasi dijadikan sampel. Berdasarkan penelitian yang diperoleh, hasil pretest $=22,46$ dalam kategori kurang sekali dan posttest $=27,86$ dalam kategori kurang dengan selisih 5,4 . Analisis statistik yang digunakan dalam penelitian ini adalah Uji t. Adapun hasil Uji t hasil perhitungan antara tes awal dan tes akhir terdapat pengaruh yang signifikan. Hasil perhitungan menyatakan bahwa nilai thitung $=16,119>t_{\text {tabel }}=1,699$ dengan taraf $\alpha=$ 0,05 maka $H_{o}$ ditolak dan $H_{a}$ diterima artinya terdapat pengaruh yang signifikan latihan variasi shooting ke arah gawang terhadap akurasi shooting dalam permainan sepak bola. Sehingga dapat disimpulkan bahwa adanya pengaruh latihan variasi shooting ke arah gawang terhadap akurasi shooting dalam permainan sepak bola pada pemain U-14 SSB Tunas Muda Bengkulu.
\end{abstract}

Kata Kunci: Latihan, Akurasi, Shooting.

\begin{abstract}
This study aims to determine the effect of variation shooting into the goal on shooting accuracy in the game of football. The population in this study were 30 players Age 14 SSB Shooter Young Bengkulu. Experimental study using one group pretest-posttest design research with sampling technique is total sampling, where the entire population is sampled. Based on the research, the result of pretest $=22.46$ in the category of less once and posttest $=27.86$ in the category less by the difference of 5.4. Statistical analysis used in this research is t test. The result of t test result of calculation between initial test and final test there is significant influence. The calculation result states that $t$ count $=16,119>t$ table $=1,699$ with level $\alpha=0,05$ then Ho rejected and Ha accepted meaning there is significant influence of shooting variation into the goal on shooting accuracy in the game of football. So it can be concluded that the influence of shooting variation into the goal on shooting accuracy in the game of football on the player Age 14 SSB Shooter Young Bengkulu.
\end{abstract}

Keywords: Exercise, Accuracy, Shooting. 


\section{PENDAHULUAN}

Sepak bola adalah salah satu cabang yang digemari oleh masyarakat Indonesia. Olahraga ini sudah memasyarakat di kalangan bawah hingga kalangan atas. Di Indonesia, sepak bola semakin semarak dengan diselenggarakannya kompetisi dalam negeri yaitu Liga Indonesia.

Dengan adanya kompetisi diharapkan akan mampu menghasilkan pemain-pemain handal yang dapat mengangkat prestasi sepak bola. Salah satu penentu keberhasilan menciptakan pemain handal dalam sepak bola adalah dengan pembinaan yang benar usia dini di Sekolah Sepak bola. Pembinaan pemain sepak bola usia dini dilakukan melalui wadah yaitu Sekolah Sepak bola. SSB adalah sekolah yang mempelajari tentang permainan sepak bola yang berfungsi mengembangkan potensi yang dimiliki atlet serta menjadi wadah pembinaan sepak bola usia dini.

Menendang bola merupakan teknik dasar yang harus dikuasai untuk menjadi pemain sepak bola, apabila pemain memiliki teknik dasar menendang bola dengan baik, maka mereka akan dapat bermain secara efektif dan efisien.

Pada pemain U-14 SSB Tunas Muda Bengkulu kemampuan akurasi shooting pemain masih rendah dan belum maksimal, kondisi fisik pemain yang kurang baik, shooting yang dilakukan pemain saat latihan tidak dapat memanfaatkan peluang karena hasil shooting melebar, melambung diatas mistar gawang atau terbentur pemain bertahan lawan, pemain U-14 SSB Tunas Muda Bengkulu dinilai kurang antusias dan kurang tertarik dengan latihan shooting yang diberikan oleh pelatih sehingga proses latihan kurang maksimal, kurangnya latihan variasi shooting untuk meningkatkan akurasi shooting pemain U-14 SSB Tunas Muda Bengkulu, kurangnya mental pemain pada saat melakukan shooting, perlu adanya penelitian tentang pengaruh latihan variasi shooting ke arah gawang terhadap akurasi shooting dalam permaianan sepak bola pada pemain U-14 SSB Tunas Muda Bengkulu. Akurasi merupakan keakuratan, ketepatan, kejituan dan kecermatan dan menyongsong, menyundul dan menendang bola ke gawang atau mengumpan bola ke kawan sendiri.

Shooting adalah tendangan yang dilakukan pemain sepak bola dengan kekuatan punggung kaki untuk menciptakan gol ke gawang lawan. Shooting merupakan teknik dasar sepak bola yang harus dikuasai pemain terutama pemain depan, karena peluang paling besar untuk menciptakan gol adalah menembak bola dengan kekuatan kaki ke gawang lawan dengan akurat.Teknik shooting yang paling baik dilakukan dengan punggung kaki. Kunci kekuatan shooting ada pada kekuatan tungkai dan sudut pengambilan tendangan yang optimal.

Latihan adalah aktifitas untuk meningkatkan kualitas fungsi sistem organ tubuh manusia sehingga mempermudah atlet dalam penyempurnaan geraknya (Apta dan Febi, 2015:47). Dan latihan adalah proses dimana seseorang atlet dipersiapkan untuk peforma tertinggi (Bompa dan Gregory, 2009:2).

Secara umum tujuan latihan adalah membantu para pembina, pelatih, guru olahraga agar dapat menerapkan dan memiliki kemampuan konseptual serta keterampilan dalam membantu mengungkapkan potensi atlet mencapai puncak prestasi (Apta dan Febi, 2015:49).

Menurut Thondrik (Rahyubi, 2012:164) pada teori belajar law of exercise yang menyatakan bahwa prinsip hukum latihan menunjukkan prinsip utama dalam belajar adalah pengulangan, semakin sering diulangi materi pelajaran akan semakin dikuasai.

Dari sudut pandang penyerangan, tujuan sepak bola adalah melakukan shooting ke gawang. Seorang pemain harus menguasai keterampilan dasar menendang bola dan selanjutnya mengembangkan sederetan teknik shooting yang memungkinkan untuk melakukan tendangan 
shooting dan mencetak gol dari berbagai posisi dilapangan. Cara yang paling tepat untuk mengembangkan akurasi shooting adalah melatih tendangan shooting berkalikali menggunakan teknik yang benar (Danny Mielke, 2003:67).

Seorang yang mampu mengumpan dan menggiring bola dengan baik tanpa mampu melakukan shooting dengan baik bukanlah pemain yang menguasai teknik dasar sepak bola, karena bermain sepak bola bertujuan mencetak goal sedangkan bermain cantik tidak diberi nilai.Pemain sepak bola diharuskan bisa menendang bola ke gawang lawan dengan baik (Timo Scheunemann, 2012:188).

Bentuk latihan variasi shooting adalah sebagai berikut: 1. Latihan variasi mengumpan bola ke kiri atau ke kanan di lanjutkan shooting ke arah gawang, 2 . Latihan shooting menggunakan variasi mengumpan bola dan rotasi lari, 3. Latihan variasi shooting ke arah gawang dengan lanjutan sprint, 4. Latihan variasi shooting di lanjutkan dengan lomba sprint, 5. Latihan variasi shooting dalam format game.

\section{METODE}

Metode ini melatih variasi shooting ke arah gawang, yang merupakan latihan 5 variasi shooting. Kelebihan dari latihan ini ketika pemain melakukan latihan variasi shooting kearah gawang akan meningkatkan fisik dan akurasi shooting pemain akan bertambah.

Penelitian ini berjenis penelitian eksperimen. Penelitian ini dibagi menjadi 3 tahapan yakni pretest, pemberian perlakuan (treatment), dan pos test. Desain yang di gunakan dalam penelitian ini adalah one group pretest-posttest design. Dalam design ini tidak menggunakan kelompok kontrol dan subyek tidak ditempatkan secara acak.

Kelebihan dari design ini adalah dilakukannya pretest dan posttest sehingga dapat diketahui pasti perbedaan hasil akibat perlakuan yang diberikan (treatment).
Populasi dalam penelitian ini adalah seluruh pemain U-14 SSB Tunas Muda Bengkulu, teknik pengambilan sampel dalam penelitian ini menggunakan teknik total sampling, dimana seluruh populasi di jadikan sampel yaitu pemain kelompok usia 14 tahun SSB Tunas Muda Bengkulu yang berjumlah 30 orang.

Dalam penelitian ini terdapat dua variabel yaitu variabel bebas dan variabel terikat. Variabel bebas dalam penelitian ini adalah latihan variasi shooting ke arah gawang. Adapun yang menjadi variabel terikat dalam penelitian ini adalah akurasi shooting pemain U-14 SSB Tunas Muda Bengkulu. Teknik pengumpulan data menggunakan tes shooting at the ball dengan validitas 0,82dan reliabilitas 0,76 (Arsil, 2010:125).

\section{HASIL DAN PEMBAHASAN}

Untuk mendapatkan hasil dalam penelitian ini maka peneliti terlebih dahulu mengola data pretest dan posstest menggunakan teknik analisis data, adapun yang terdapat di dalam tekhnik analisis data adalah uji prasyarat dan uji hipotesis. Di dalam uji prasyarat ada 2 perhitungan yang dilakukan peneliti. Yang pertama menghitung normalitas data pretest dan posstest.

Yang kedua menghitung homogenitas data pretest dan data posttest menggunakan uji f. Setelah selesai dengan uji prasyarat, barulah peneliti mengerjakan uji hipotesis dengan menggunakan uji t pengaruh. Uji t pengaruh bertujuan untuk menjawab hipotesis yang di ajukan peneliti yaitu ada tidaknya pengaruh latihan plyometric di pasir terhadap power otot tungkai siswi di SMKN1 Kota Bengkulu.

\section{1) Uji Prasyarat.}

\section{a. Penghitungan Normalitas}

Penghitungan normalitas dengan menggunakan rumus Liliefors. Hasil yang diperoleh adalah:

Tabel 1. Uji Normalitas 


\begin{tabular}{c|c|c|c}
\hline $\begin{array}{c}\text { Data } \\
\text { Penelitian }\end{array}$ & $\mathrm{L}_{\mathrm{o}}$ & $\mathrm{L}_{\text {tabel }}$ & Kesimpulan \\
\hline $\begin{array}{c}\text { Sebelum } \\
\text { Pelatihan }\end{array}$ & 0,155 & 0,161 & Distribusi \\
\hline $\begin{array}{c}\text { Sesudah } \\
\text { Pelatihan }\end{array}$ & 0,122 & 0,161 & Normal \\
\hline
\end{tabular}

Dari tabel diatas, diketahui $\mathrm{L}_{0}<\mathrm{L}_{\text {tabel, }}$ Berarti data yang di ambil dari satu kelompok eksperimen yang di teliti mempunyai distribusi Normal.

\section{b. Uji Homogenitas}

Uji homogenitas menggunakan uji $\mathrm{F}$ dengan derajat kebebasan dan taraf signifikansi $a=0,05$ pada tabel berdistribusi F. Hasil yang diperoleh adalah:

Tabel 2. Uji Homogenitas

\begin{tabular}{c|c|l|l}
\hline No & Variabel & $\begin{array}{c}\text { Standar } \\
\text { Deviasi }\end{array}$ & Varians $\left(\mathrm{S}^{2}\right)$ \\
\hline 1 & Tes Awal & 14,8 & 3,85 \\
\hline 2 & Tes Akhir & 11,4 & 3,37 \\
\hline
\end{tabular}

$$
\begin{aligned}
& F_{\text {hitung }}=\frac{\text { Varians Terbesar }}{\text { Varians Terkecil }} \\
& \text { F hitung }=\frac{14,8}{11,4}=1,29
\end{aligned}
$$

Dari perhitungan diatas didapat nilai $F_{\text {hitung }}=1,29$ sedangkan nilai $f_{\text {tabel }}$ pada taraf signifikan $a=0,05=4,17$. F Fitung $<F_{\text {tabel }}$ yaitu $1,29<4,17$ ini berarti tidak terdapat perbedaan dari masing-masing variabel atau harga variansya Homogen.

\section{Uji Hipotesis}

Penelitian ini bertujuan untuk mengetahui pengaruh latihan variasi shooting kearah gawang terhadap akurasi shooting dalam permainan Sepak bola pada pemain U-14 SSB Tunas Muda Bengkulu.

Analisis data yang digunakan untuk menjawab hipotesis yang diajukan yaitu ada tidaknya pengaruh latihan variasi shooting ke arah gawang terhadap akurasi shooting dalam permainan Sepak bola pada pemain U14 SSB Tunas Muda Bengkulu.
Setelah dilakukan penghitungan normalitas dan homogenitas, selanjutnya dilakukan pengujian hipotesis menggunakan uji-t sebagai berikut:

Tabel 3. Uji T Berdasarkan hasil tes awal dan tes akhir

\begin{tabular}{c|c|c|c|c}
\hline \multirow{2}{*}{ No } & \multirow{2}{*}{$\mathrm{n}$} & \multicolumn{2}{|c|}{$\begin{array}{r}\text { Tes Awal dan } \\
\text { Tes Akhir }\end{array}$} & \multirow{2}{*}{ Ket } \\
\cline { 3 - 5 } & & $t_{\text {hitung }}$ & $t_{\text {tabel }}$ & Kesimpulan \\
\hline 1 & 30 & 16,119 & 1,699 & Signifikan \\
\hline
\end{tabular}

Dari hasil data yang terkumpul maka penghitungan menunjukkan $t_{\text {hitung }}$ sebesar 16,119> $t_{\text {tabel }}=1,699$. Berarti signifikan. Selanjutnya hipotesis yang menyatakan bahwa ada pengaruh latihan variasi shooting ke arah gawang terhadap akurasi shooting dalam permainan Sepak bola pada pemain U14 SSB Tunas Muda Bengkulu, diterima.

Latihan yang dilaksanakan selama 16 kali pertemuan terbukti berhasil memberikan pengaruh terhadap akurasi shooting pada pemain U-14 SSB Tunas Muda Bengkulu. Peningkatan akurasi shooting terlihat pada perbandingan perubahan ratarata pretest dan posttest. Dari data yang sudah diperoleh, hasil pretest sebesar 22,46 terdapat 22 pemain dalam kategori kurang sekali dan hasil rata-rata posttest sebesar 27,86 terdapat 8 pemain dalam kategori kurang dengan selisih 5,4 meskipun kategorinya kurang tetapi hasil pencatatan data meningkat dilihat dari skore yang didapat.

Mengingat pentingnya akurasi shooting dalam permainan sepak bola maka perlu sekali upaya untuk meningkatkan akurasi shooting pada pemain U-14 SSB Tunas Muda Bengkulu. Akurasi shooting pemain dapat meningkat apabila latihan dilakukan secara terprogram, dan dilakukan dengan benar Dengan demikian dapat di simpulkan bahwa penelitian yang telah dilakukan dengan pemberian latihan variasi shooting ke arah gawang terbukti dapat meningkatkan akurasi shooting pada pemain U-14 SSB Tunas Muda Bengkulu. 


\section{PENUTUP}

Simpulan

Berdasarkan hasil penelitian diatas dapat di simpulkan latihan variasi shooting ke arah gawang berpengaruh terhadap akurasi shooting pada pemain U-14 SSB Tunas Muda Bengkulu. Peningkatan akurasi shooting terlihat pada perbandingan perubahan ratarata pretest dan posttest. Dari data yang sudah diperoleh, hasil pretest sebesar 22,46 dalam kategori kurang sekali dan hasil ratarata posttest sebesar 27,86 dalam kategori kurang dengan selisih 5,4.

Hasil penelitian menunjukkan bahwa selisih mean antara pretest dan posttest pemain setelah mengikuti program latihan variasi shooting ke arah gawang sebanyak 16 kali pertemuan dapat menunjukkan peningkatan terhadap akurasi shooting pemain. Dengan latihan variasi shooting dapat menampilkan teknik dasar akurasi yang baik khusus nya pada akurasi shooting diharapkan dapat meningkatkan prestasi dalam permainan Sepak bola karena akurasi yang baik seorang atlet dapat memiliki rasa percaya diri dalam menampilkan permainan terbaiknya sehingga akan lebih mudah untuk menciptakan kemenangan tim dan pencapaian prestasi yang optimal.

Dan dari hasil $t_{\text {hitung }}=16,119>$ $t_{\text {tabel }}=1,699$. Maka data hasil pretest dan posstest di nyatakan signifikan. Dengan demikian hipotesis yang berbunyi "Ada pengaruh latihan variasi shooting ke arah gawang terhadap akurasi shooting dalam permainan sepak bola pada pemain U-14 SSB Tunas Muda Bengkulu", diterima.

\section{Saran}

1. Bagi pelatih sepak bola agar dapat memberikan materi latihan variasi shooting ke

2. arah gawang dalam permainan sepak bola sehingga dapat meningkatkan akurasi shooting pemain.

3. Bagi atlit Sepak bola diharapkan dapat melakukan latihan variasi shooting ke arah gawang terhadap akurasi shooting dalam permainan Sepak bola sehingga mendapatkan hasil yang optimal sesuai apa yang diharapkan.

4. Bagi peneliti sendiri diharapkan dapat lebih banyak memperoleh pendukung baik dari segi referensi ataupun informasi dari para senior dalam penelitian yang dilakukan.

\section{DAFTAR PUSTAKA}

Abdul Rohim. (2008). Bermain Sepak bola. Semarang: Aneka IImu.

Alexon. (2012). Statistika untuk Penelitian Pendidikan. Bengkulu: Unit Penerbitan FKIP Universitas Bengkulu.

Arsil. (2010). Evaluasi Pendidikan Jasmani Olahraga. Malang: Wineka Media.

Bompa, T.O. (1994). Theory and Methedology of Training, Third edition, Toronto, Ontorio Canada: Kendall/Hunts Publishing Company.

Danny Mielke. (2007). Dasar-Dasar Sepak Bola. Bandung: Pakar Raya.

Edwin Vasaloga. (2014). Pengaruh Latihan Shooting Dengan Punggung Kaki Bagian Dalam Dan Punggung Kaki Penuh Terhadap Ketepatan Shooting Di Akademi Sepak bola Sriwijaya F. Skripsi. Yogyakarta: Universitas Negeri Yogyakarta.

Herwin. (2004). Keterampilan Sepak bola Dasar. Yogyakarta: FIK UNY.

Johan Pambudi. (2013). Pengaruh Latihan Tendangan Penalti Menggunakan Sasaran Tetap Dan Sasaran Berubah Terhadap Akurasi Tendangan Penalti Pada Pemain UKM Sepak Bola UNNES. Skripsi. Semarang: UNNES.

Mikha Agus Widiyanto. (2013). Statistika Terapan. Konsep dan Aplikasi dalam Penelitian Bidang Pendidikan, Psikologi dan IImu Sosial Lainnya. Jakarta: PT Elex Media Komputindo.

Mylsidayu, Apta dan Kurniawan, Febi. (2015). IImu kepelatihan Dasar. Bandung: Alfabeta. 
Rahyubi, Heri. (2012). Teori-Teori Belajar dan Aplikasi Pembelajaran Motorik. Majalengka: Referens.

Rushall, B.S, and Frank S. Pyke, (1990). Training for Sport and Fitness, Sourth Melbourne: The Macmillan Company of Australia PTY LTD, 107 Moray Street, Sadoso.

Lukman Heriyanto. (2016). Pengaruh Latihan Variasi Menendang Ke Berbagai Sasaran Untuk Meningkatkan Ketepatan Shooting Menggunakan Punggung Kaki Siswa Yang Mengikuti Ekstrakurikuler Futsal Di SMP N 2 Depok. Skripsi. Yogyakarta: Universitas Negeri Yogyakarta.

Schmidt, J.M. \& Lee TD. (2005). Motor Control and Learning.A Behavioral Emphasis. Champaign (IL): Human Kinetics.

Subagyo Irianto. (2010). Pedoman Pelaksanaan Tes Kecakapan "David Lee" untuk Sekolah Sepakbola (SSB) Kelompok Umur 14-15 Tahun. Yogyakarta: FIK UNY.

Sucipto. (2000). Sepakbola. Jakarta: Depdikbud.

Sugiyono. (2006). Metode Penelitian Kuantitatif Kualitatif Dan $R \quad \& \quad D$. Bandung: Alfabeta.

Supardi. (2017). Statistika Penelitian Pendidikan. Depok: Rajawali Pers.

Timo Scheunemann. (2012). Kurikulum \& Pedoman Dasar Sepak Bola Indonesia Indonesia. Jakarta: PSSI.

Sukatamsi. (2003). Permainan Besar I Sepak Bola. Jakarta: Universitas Terbuka. 